\title{
Application of the GREAT-ER model for environmental risk assessment of nonylphenol and nonylphenol ethoxylates in China
}

\author{
Lai Zhang ${ }^{1} \cdot{\text { Yan } \mathrm{Cao}^{1} \cdot \text { Xuewen Hao }^{1} \cdot \text { Yongyong Zhang }}^{2} \cdot$ Jianguo Liu $^{1}$ (D)
}

Received: 1 December 2014 / Accepted: 1 September 2015/Published online: 10 September 2015

(C) Springer-Verlag Berlin Heidelberg 2015

\begin{abstract}
The environmental risk presented by "down-thedrain" chemicals to receiving rivers in large urban areas has received increasing attention in recent years. Geo-referenced Regional Environmental Assessment Tool for European Rivers (GREAT-ER) is a typical river catchment model that has been specifically developed for the risk assessment of these chemicals and applied in many European rivers. By utilizing the new version of the model, GREAT-ER 3.0, which is the first completely open source software for worldwide application, this study represents the first attempt to conduct an application of GREAT-ER in the Wenyu River of China. Aquatic exposure simulation and an environmental risk assessment of nonylphenol (NP) and its environmental precursor nonylphenol ethoxylates (NPEOs) were conducted effectively by GREAT-ER model, since NP is one of typical endocrine disrupting chemicals (EDCs) and its environmental precursor NPEOs as a "down-the-drain" chemical are extensively used
\end{abstract}

Responsible editor: Michael Matthies

Electronic supplementary material The online version of this article (doi:10.1007/s11356-015-5352-3) contains supplementary material, which is available to authorized users.

Jianguo Liu

jgliu@pku.edu.cn

1 State Key Joint Laboratory for Environmental Simulation and Pollution Control, College of Environmental Sciences and Engineering, Peking University, Beijing 100871, People's Republic of China

2 Key Laboratory of Water Cycle and Related Land Surface Processes, Institute of Geographic Sciences and Natural Resources Research, Chinese Academy of Sciences, Beijing, People's Republic of China in China. In the result, the predicted environmental concentrations (PECs) of NP and NPEOs in the water of Wenyu River were 538 and $4320 \mathrm{ng} / \mathrm{L}$, respectively, at the regional scale, and 1210 and $8990 \mathrm{ng} / \mathrm{L}$, respectively, at the local scale. From the results profile of the RCR, the combination of high emissions from large STPs with insufficient dilution of the river caused the high RCR. The PECs of NP in the sediment were in the range of $216.8-8218.3 \mathrm{ng} / \mathrm{g}$ (dry weight), which was consistent with the available monitoring data. The study showed the worldwide applicability and reliability of GREAT-ER as a river catchment model for the risk assessment of these chemicals and also revealed the general environmental risks presented by NP and NPEOs in the Wenyu River catchment in Beijing due to the extensive use of these chemicals. The results suggest that specific control or treatment measures are probably warranted for these chemicals to reduce their discharge in major cities.

Keywords "Down-the-drain" chemicals · Risk assessment . GREAT-ER · Catchment establishment · NP and NPEOs

\section{Introduction}

The environmental risks of "down-the-drain" chemicals, which are usually caused by their use in various industrial or household chemical products and the subsequent discharge into rivers via sewage treatment plants (STPs) in urban areas, have attracted increasing attention in recent years (DiamantiKandarakis et al. 2009; Kavlock et al. 1996; Keller 2006; Koormann et al. 2006; USEPA 2006). Especially, a part of "down-the-drain" chemicals such as phthalates (PAEs), bisphenol A (BPA), and nonylphenol (NP) is considered to be endocrine disrupting chemicals (EDCs) (EU 2008; USEPA 2006; An and Hu 2006; Welshons et al. 2003). The use of 
nonylphenol and nonylphenol ethoxylates has been severely restricted in developed countries, but they are still widely used in China. Nonylphenol is present in high concentrations in the aquatic environment in China. Numerous monitoring studies have indicated that contamination levels of NP and NPEOs (In this paper, the term "NP and NPEOs" represents a series of isomeric compounds of nonylphenol and nonylphenol ethoxylates, a term incorporating a number of chemically different compounds) have reached $1000 \mathrm{ng} / \mathrm{L}$ in rivers and are as high as $7000 \mathrm{ng} / \mathrm{g}$ in sediments in major industrialized urban areas of China, which represent a relatively high aquatic environmental exposure level (Chen et al. 2006; Fu et al. 2008; Hou et al. 2005; Shao et al. 2002; Wang et al. 2010; $\mathrm{Xu}$ et al. 2006; Yu et al. 2008; Zhao et al. 2009). However, most of these were conducted using a monitoring methodology, which may not reflect typical or average concentrations, since the chemical analyses are limited by the spatial and temporal resolutions of sampling. In contrast, modeled concentrations generally reflect typical or average concentrations required for detailed environmental risk assessment (Leeuwen and Vermeire 2007). To assess the environmental risks of "down-the-drain" chemicals in rivers, GREAT-ER has proven to be a well-developed and reliable model that simulates environmental concentrations and provides risk distributions of these chemicals in a series of individual European catchments (Cunningham et al. 2010; Hannah et al. 2009; Hüffmeyer et al. 2009; Sabaliunas et al. 2003). By establishing a European digital river network based on input data including hydrological data, emission information, and other parameters, GREAT-ER has been successfully used to simulate environmental concentrations and assess the environmental risks of surfactants such as alkylbenzene sulfonate (Fox et al. 2000), drugs such as ethinyl estradiol and aspirin (Schowanek and Webb 2002), and EDCs such as estradiol and estrogen estrone (Sabaliunas et al. 2003; Sumpter et al. 2006). GREAT-ER is also used to simulate emerging contaminants diclofenac in Spain recently (Aldekoa et al. 2013). In 2012, a new version of the model with the first open source software for a river catchment self-establishment was published (i.e., GREAT-ER 3.0), providing a valuable opportunity and technical support for its worldwide application (Schowanek et al. 2012). New version of the GREAT-ER software is applied for the prediction of spatially explicit exposure concentrations of pharmaceutical diclofenac in Germany (Kehrein et al. 2015).

In this study, the use of the GREAT-ER model is introduced to a Chinese environment, to conduct a practical environmental risk assessment of NP and its environmental precursor NPEOs in the Wenyu River catchment in Beijing, China. The catchment is typical receiving water for "down-the-drain" chemicals, and NP and NPEO monitoring data have been obtained for this environment; however, no environmental risk assessment of the river catchment has been undertaken.

\section{Materials and methods}

\section{NP and NPEOs}

In this study, the term "NP" denotes a mixture of various isomers of nonylphenol, predominantly para-substituted nonylphenol, with small amounts of ortho-substituted phenol and 2,4-dinonylphenol, which represent numerous branched structures that occur within the nine-carbon group. The final technical mixtures of NP contain more than 22 isomers of 4 substituted monoalkylphenols (Thiele et al. 2004; Wheeler et al. 1997).

NP is mainly used as an intermediate for the production of NPEOs which are nonionic surfactants widely used in industrial and household detergents, cleaning agents, emulsifiers, and dispersing agents (An and Hu 2006). The term "NPEOs" denotes a mixture of compounds with different chain ethoxylation of nonylphenol, which contains an ethoxylate chain with a recalcitrance that increases with decreasing number of ethoxylate groups. Under ambient conditions, numerous NPs can be obtained from the breakdown of NPEOs, which is the main source of NP contamination. NP is a wellknown EDC, which interferes with the hormonal and endocrine systems of organisms. Although the NP isomers in technical NP mixtures may differ in the strength of their endocrine activity (Preuss et al. 2006), the model applied here was simplified by assuming that they had approximately equivalent endocrine activity, and the sum of concentrations of NP isomers was used to indicate the environmental risk of this kind of EDC.

\section{Model and target catchment}

A schematic diagram of the GREAT-ER modeling in our study is shown in Fig. 1, which is based on Boeije (1999) and Feijtel et al. (1997), indicating the modeling processes and relevant key parameters in the study. First, a river catchment for simulation of the emission and distribution of "down-the-drain" chemicals needs to be established, which can also be used for other similar chemicals. This requires not only a collection of geographic data which based on geographic information system (GIS) and hydrologic information with flow volume, flow velocity, and latitude/longitude coordinates of each segment for the river catchment, but also population data received by STP and types, coordinates, sewage treatment capacity, and removal of the STPs in the catchment. A practical modeling scenario for the target "down-the-drain" chemicals can be built according to their emission inventory, the removal rate of the chemicals by STPs, and the migration and transformation rates in the river. Finally, the concentrations of the targeted "down-the-drain" chemicals in the water and sediment of the river catchment and the environmental risk implications are derived by the modeling. 
Fig. 1 The GREAT-ER

modelling processes in the study

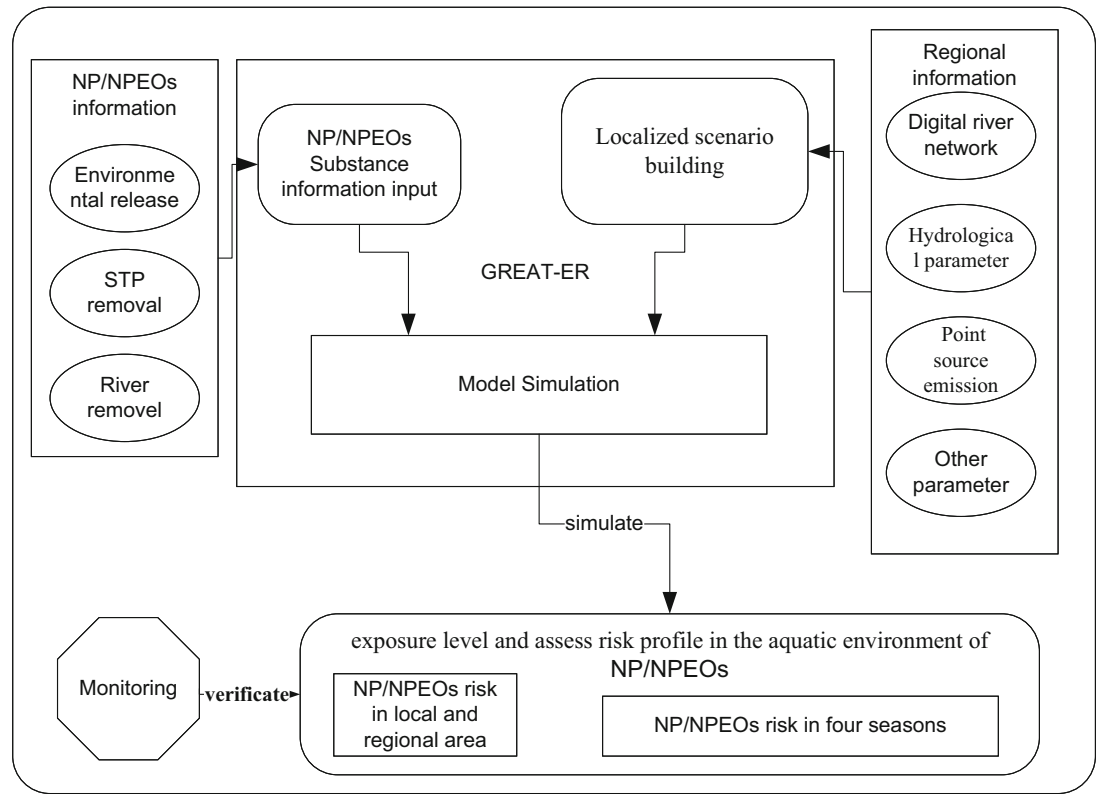

The Wenyu River catchment was selected for this GREATER modeling study. The Wenyu River catchment is located in the northeast of Beijing, as shown in Fig. 2. Fundamental and general information about the catchment area, the main streams and tributaries, the total sewage discharge, and sewage treatment works are provided in the supporting information. The Wenyu River flows through the northern and eastern regions of Beijing, through a high density of residential and industrial areas, and is a significant receiving water for "down-the-drain" chemicals in this urban area (Zheng et al. 2007). The information and parameters required to construct a GREAT-ER model for this catchment can be easily obtained, and hence, the Wenyu River may be selected as an ideal site for study of NP and NPEOs (Lei et al. 2008a, b).

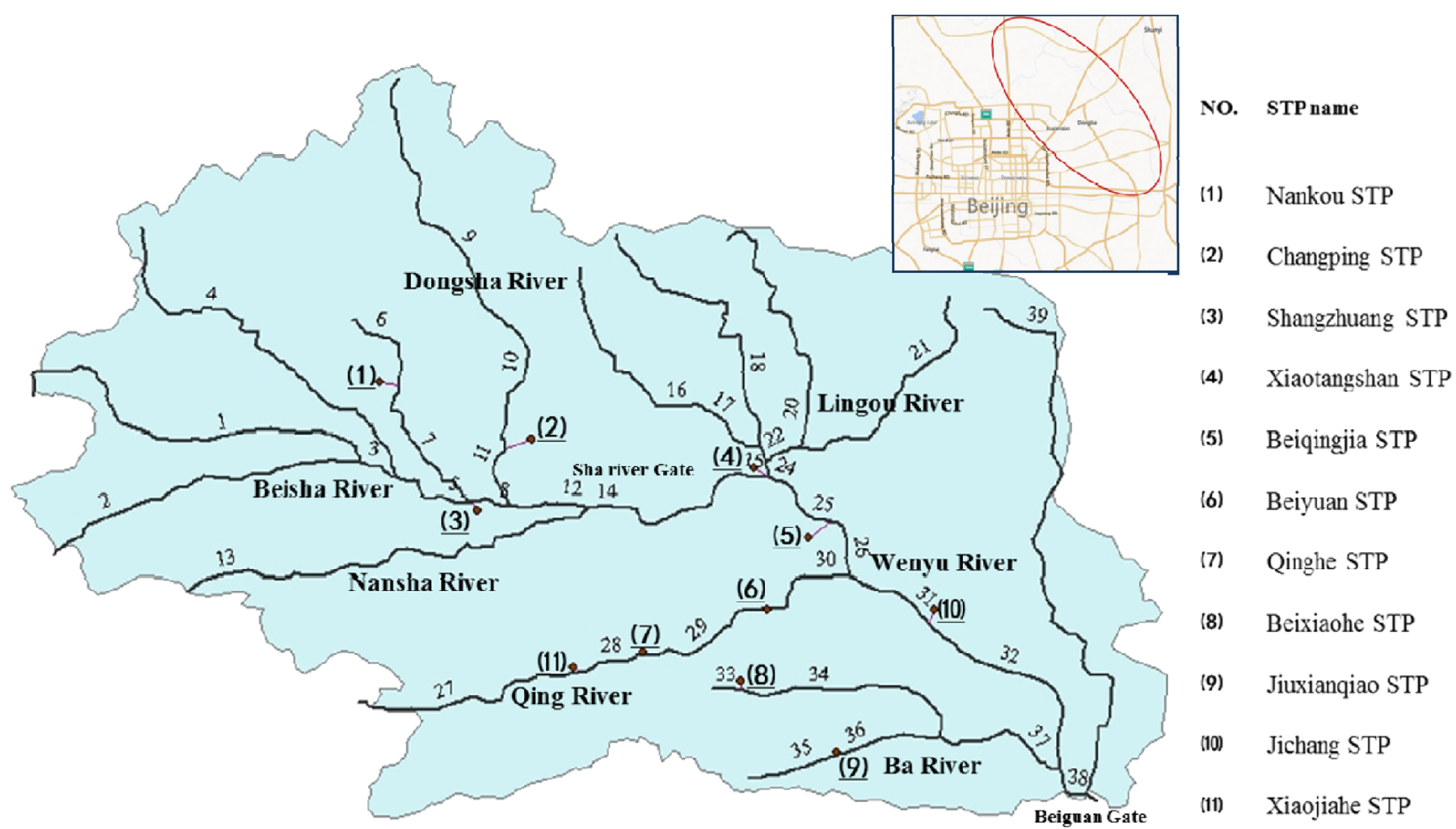

Fig. 2 The digital network map of the Wenyu River catchment that was built for GREAT-ER 


\section{Catchment establishment for modeling}

The building of a catchment of the local river for GREAT-ER modeling is a fundamental part of this study. First, we built a digital network map of the Wenyu River catchment in Beijing based on the digital elevation model (DEM) map and GIS simulation (Fig. 2) in which flow direction corrections were made for each river segment according to the actual situation. Second, the river segments in this catchment were coded with numbers from 1 to 40 shown in Fig. 2, and normal stream flows for each river segment were obtained from hydrological monitoring data. However, in this case, the current hydrological monitoring data for the Wenyu River catchment were insufficient for generating detailed stream flows of the river, and instead, Soil and Water Assessment Tool (SWAT; Arnold et al. 2012), a hydrology and water quality model, was used to simulate stream flows of each river segment in the catchment. The SWAT simulation results on flow volumes have been well validated with onsite monitoring data (Tang et al. 2010; Zhang et al. 2009). In practice, stream flow values of the river for modeling were obtained based on the results of simulated outlet flows for each segment by SWAT, following the necessary data transformation and correction (hydrologic information of these 40 segments were shown in Table S1 in supporting information). Certain other catchment establishment data, such as flow rates and river depths, were calculated by empirical formulas contained in the modules of GREATER itself.

The third important part is the correct assignment of STPs to the respective river segments. Because "down-the-drain" chemicals are released to the aquatic environment through STPs from household and industrial processes, STPs were selected as point sources of these chemicals in this study. Information regarding STPs in the Wenyu River catchment was collected based on field research and expert inquiry, and mainly included the location of STPs, the population served, sewage flow, and operating conditions. Eleven STPs with large discharge volumes that flow into the Wenyu River catchment were selected as point sources for the catchment building phase of the study; the discharge volume from these forms $93 \%$ of the total discharge and most emissions of "downthe-drain" chemical can be accounted for by considering these 11 STPs. The location, daily wastewater flow, and STP treatment type of each STP are shown in Table S2 (Supporting Information).

\section{Simulation scenario building}

\section{Estimation of the emission of NP and NPEOs within the catchment}

NP (the physicochemical properties and introduction were shown in supporting information) is not only an industrial intermediate for NPEOs but also a metabolite of nonylphenol ethoxylates (NPEOs) in the aquatic environment. Under environmental and STP conditions, long-chain NPEOs will break down to NP, nonylphenol monoethoxylate $\left(\mathrm{NPEO}_{1}\right)$ and nonylphenol diethoxylate $\left(\mathrm{NPEO}_{2}\right)$, and other metabolites. In this paper, the emission of NPs is considered from two sources: NPEO degradation from industrial and household use and NPEO breakdown under STP conditions. NP concentrations are then used as a direct and easily measurable indicator in the risk assessment.

According to our survey on NP and NPEOs industrial sources in Beijing area, there were no industrial sources of NP and NPEOs in our studying area and the only few industrial sources all located at the southeast edge zone of Beijing, which is almost the downstream end of the Wenyu River and out of our studying areas. Then, the residential emission through STPs is the dominant source of NP and NPEOs in the Wenyu River catchment in the study. Because more than $95 \%$ of all wastewater in Beijing is treated, the NP and NPEOs used in this area were all assumed to have been processed by a STP, and that fugitive emissions of NP and NPEOs could be neglected. According to the GREAT-ER model, the per capita chemical consumption (PCC) of NP and NPEOs in the Wenyu River catchment needs to be estimated to simulate their emission from STPs. Given that there is no statistical information about NP and NPEOs consumption in the target area, a practical method based on the monitored STP influent concentration ranges of NP and NPEOs, total influent flows per year for each STP, and the population served by the STPs was adopted to estimate the PCCs of NP and NPEOs (Balaam et al. 2010; Whelan et al. 2012), which can be calculated by the following equation:

$P C C=\frac{C_{\text {in } \mathrm{f}} \cdot M \cdot Q_{\text {in }}}{P}$

where PCC is the annual per capita emission ( $\mathrm{kg} / \mathrm{cap} /$ year), $\mathrm{C}_{\text {inf }}$ is the STP influent concentration $(\mathrm{mol} / \mathrm{L})$ for each point source, $\mathrm{M}$ is the molecular weight $(\mathrm{g} / \mathrm{mol})$ for NP and NPEOs in this study, $Q_{\text {inf }}$ is the STP influent volume $\left(\mathrm{m}^{3} /\right.$ day), and $\mathrm{P}$ is the population served by the STP (cap).

The influent concentration of NP only represents emission from NPEOs degradation used as a surfactant and that of NPEOs stands for the emission without degradation into the STP. According to the monitoring data, the observed NP and NPEOs influent concentration in four major STPs of the Wenyu River catchment were in range of 0.028 $0.095 \mu \mathrm{mol} / \mathrm{L}$ for NP and $0.116 \sim 0.365 \mu \mathrm{mol} / \mathrm{L}$ for NPEOs (Hao et al. 2007; Hou and Sun 2006; Lian et al. 2009). Average concentrations of NP and NPEOs of these four major 
STPs were used to calculate their PCCs by equation (1) according to an investigation of the influent volume and population served of the STPs in the Wenyu River catchment (shown in the Table S2 in supporting information). Average PCC values of NP and NPEO were $(5.73 \pm 1.62) \times 10-4 \mathrm{~kg} /$ cap/year and $(4.24 \pm 0.47) \times 10-3 \mathrm{~kg} / \mathrm{cap} /$ year, respectively. In the simulations, these average values were used as constant input for all STPs.

\section{NP and NPEOs removal by STPS}

The part is on the STP removal of NP and NPEOs during the sewage treatment. The NP and NPEOs removal rates by STPs are a basic parameters required to model their distribution by GREAT-ER. Many studies of the fate and degradation of NP and NPEOs in STPs in China are available, but a study conducted by Lian et al. (2009) in four types of STPs in Beijing provides the most relevant references for our study. In Lian et al. (2009) study, the removal rates of NP and NPEOs in STPs were investigated in four STPs that used different types of treatment processes, with a biomembrane and an oxidation ditch. The average influent and effluent concentration of NP in activated sludge (AS) is 0.034 and $0.001 \mu \mathrm{mol} / \mathrm{L}$, respectively. Also in the trickling filter (TF), the average influent and effluent concentration of NP is 0.062 and $0.001 \mu \mathrm{mol} / \mathrm{L}$, respectively. The total removal rate of NP in activated sludge is $97.1 \%$ and in the trickling filter is $98.4 \%$. The individual removal rates of NP and NPEOs during sewage treatment must be considered separately. According to Lian et al (2009), the NPEOs concentration is 0.149 and $0.019 \mu \mathrm{mol} / \mathrm{L}$ in the inlet and outlet of activated sludge, and 0.308 and $0.030 \mu \mathrm{mol} / \mathrm{L}$ for the trickling filter, respectively. The NPEO removal rate in the AS and TF can be considered to be 87.2 and $90.2 \%$.

\section{Removal of NP and NPEOs in rivers and sediment}

After the STP removal of NP and NPEOs during the sewage treatment, the removal rate of NP and NPEOs in the aquatic environment of the river is another key factor for the simulation of their concentration and distribution in the environment. Generally, the in-river removal processes of NP and NPEOs should comply with first-order kinetics. Sundaram and Szeto (1981) indicated that the halflife of NP in a river was about 2.5-16.5 days in a study based on the open environment and experimental conditions. Other studies have also concluded that the half-life of NP in surface water ranges from 8.5 to 30 days (Nielsen et al. 1999; Sumpter et al. 2006). Based on the relationship between half-life and the first-order reaction rate shown in Eq. (2), and also taking into account volatilization, sedimentation, and degradation processes, the in- river removal rate of NP was inferred as 0.0034-0.0115/ $\mathrm{h}$ using the following formula,

$k=\frac{\operatorname{In} 2}{H L}$

where HL is the half-life of chemicals (h) and $\mathrm{k}$ is the first-order reaction rate $(/ \mathrm{h})$.In a river environment, NPEOs have a higher degradation and removal rate than NP, with a half-life of about 4.5 days (Yoshimura 1986). Ahel et al. (1994) reported that removal rates of NPEOs were $0.0145-0.0154 / \mathrm{h}$ in high flow velocity and $0.0096 / \mathrm{h}$ in low flow velocity. Tong and Nie (2011) concluded that the removal rate of NPEOs in rivers was about $0.0103 / \mathrm{h}$. Considering the similarity of these locations to the Wenyu River, these in-river removal rates of NPEOs were used in this study.

In the sediment extension module of GREAT-ER model, the sediment concentration of NP can be affected by dissolved concentration in river. The equilibrium can be used as (3)

$C_{\text {sediment }}=f_{\mathrm{d}} \cdot C_{\text {total }} \cdot K_{\mathrm{SW}}=C_{\text {dissolved }} \cdot\left(K_{\mathrm{d} \_ \text {river }} \frac{\rho_{\mathrm{s}}}{\rho_{W}}\right)$

where $\rho^{\mathrm{s}}$ is $1300 \mathrm{~kg} / \mathrm{d} . \mathrm{w} . / 1$ for dry sediment density; $\rho w$ is $1 \mathrm{~kg} / \mathrm{L}$ for water density; and $\theta$ is 0.8 for volumetric water fraction of the sediment. The value of $\mathrm{Kd}$ _river is from the output of the GREAT-ER water model.

(Main parameters used for NP and NPEOs for simulation can be found at Table S4 in supporting information).

\section{Results and discussion}

\section{Simulation results and verification}

The distribution of NP in the Wenyu River catchment as simulated by GREAT-ER is shown in Fig. 3. The concentration of $\mathrm{NP}$ was predicted to be about $538 \mathrm{ng} / \mathrm{L}$ at the regional scale, giving the average of representative concentrations over all catchment segments. The concentration of NP in each stream segment was affected by the location of major STPs throughout the catchment and ranged from dozens to several thousands of nanogram per liter. To show the distribution of NP concentrations, the concentration scales were classified into seven levels, shown in Fig. 3. The concentrations of NP were predicted to be high in the streams close to the outlets of the major STPs, and then to decrease downstream due to the processes of migration and transformation processes in the river. The predicted concentration of NP at the outlets of the 11 STPs averaged $1210 \mathrm{ng} / \mathrm{L}$ at the local scale, which can be defined as the mean of all concentrations at the beginning of a river stretch directly receiving a treated or untreated waste water emission. 


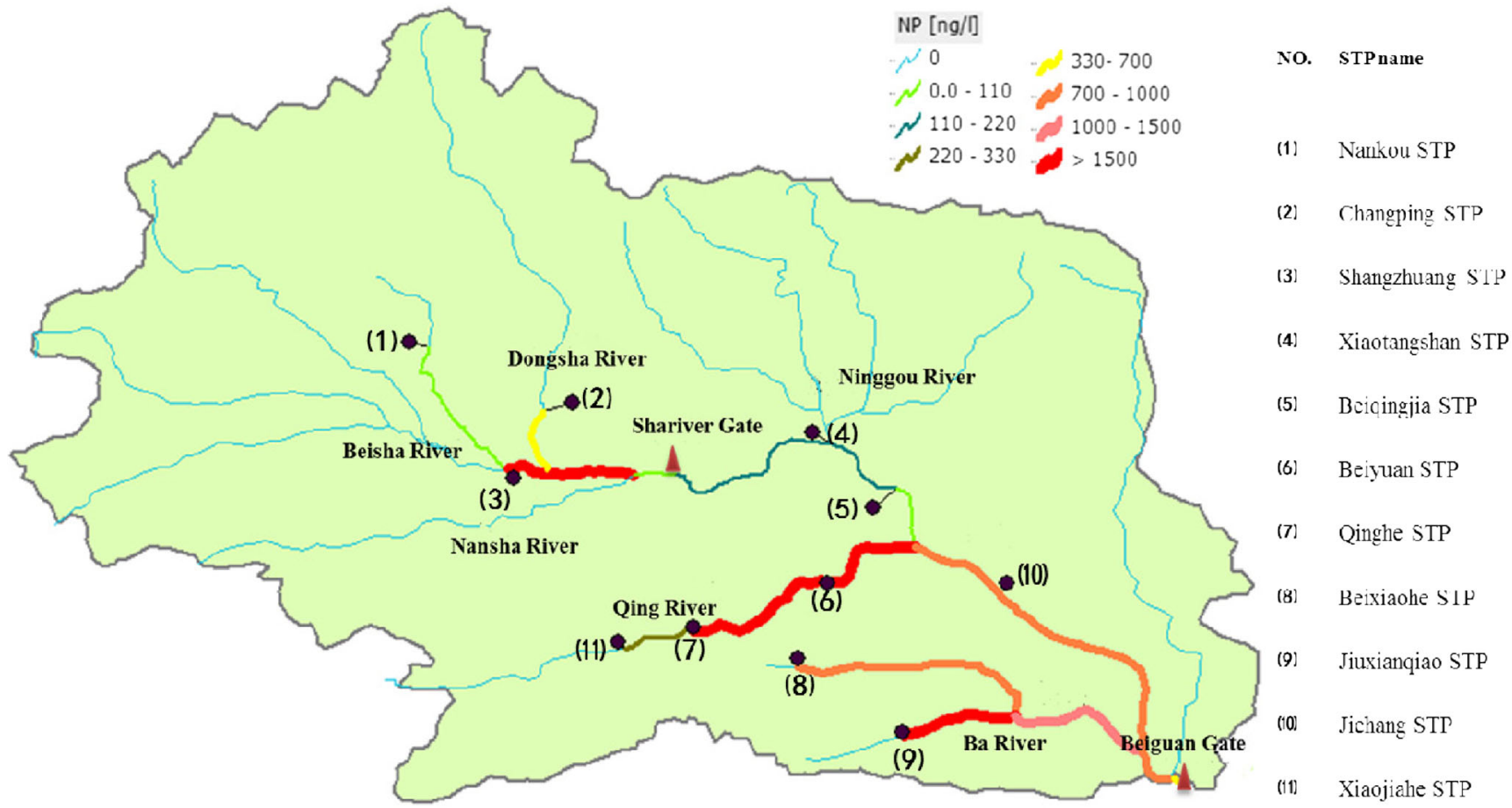

Fig. 3 Distribution of NP in the Wenyu River catchment in Beijing

According to the simulation results, downstream of the Beisha River, middle stream and downstream of the Qing River, and the Ba River segment contained high concentrations of NP (1500 ng/L in some river segments) because these segments contained the major municipal STPs within the catchment that serve a large population and have a large daily treatment capacity. The NP concentration in the segment of the upstream Sha River Gate was lower than $110 \mathrm{ng} / \mathrm{L}$, which

\begin{tabular}{lcc}
\hline No. & $\begin{array}{c}\text { Distance } \\
(\mathbf{k m})\end{array}$ & $\begin{array}{c}\text { River } \\
\text { code }\end{array}$ \\
\hline 0 & 0 & - \\
\hline 1 & 9.5 & 14 \\
\hline 2 & 15.4 & 15 \\
\hline 3 & 18.5 & 15 \\
\hline 4 & 20.5 & 15 \\
\hline 5 & 23.7 & 15 \\
\hline 6 & 31.5 & 25 \\
\hline 7 & 35.3 & 26 \\
\hline 8 & 51.4 & 32 \\
\hline 9 & 55.4 & 32 \\
\hline 10 & 61.9 & 38 \\
\hline
\end{tabular}

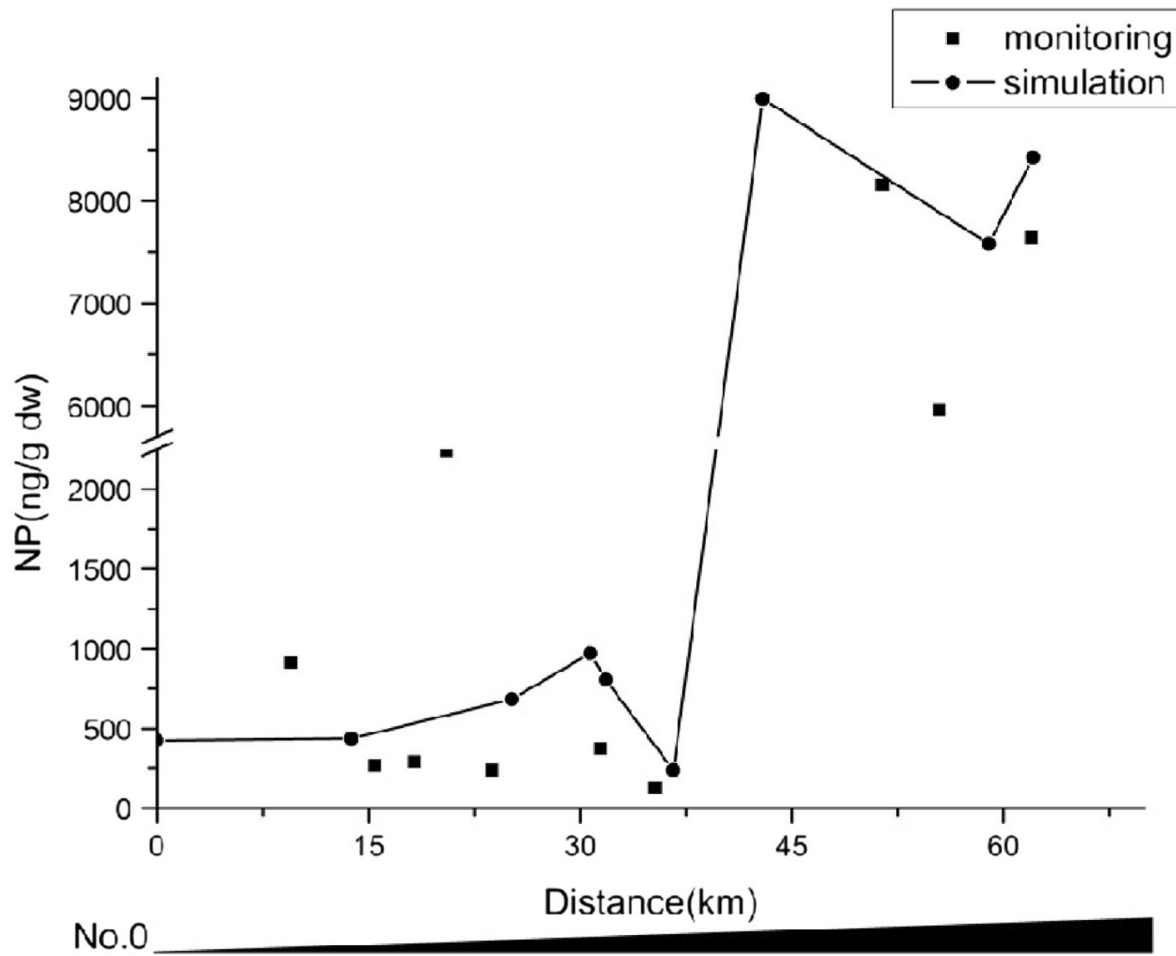

No.10

Fig. 4 Comparison of the simulated and measured concentrations of NP in mainstream sediments of the Wenyu River 
can be explained by the high flow rate of the river generated by the impounding dam there. There is a concentration drop after emission from STP 5. The concentration of NP from STP 5 is lower than that in the segment 25 which is the upstream. The NP concentration was lower than $250 \mathrm{ng} / \mathrm{L}$ in upstream from the Sha River Gate to the Qing River junction, while it was higher than $700 \mathrm{ng} / \mathrm{L}$ from the confluence of the Qing River and the mainstream to upstream Beiguan Gate, showing the distribution of high NP pollution levels in the catchment.

Simulation results predicted an environmental NPEOs concentration of $4320 \mathrm{ng} / \mathrm{L}$ at the regional scale and $8990 \mathrm{ng} / \mathrm{L}$ at the local scale. Studies have shown that long-chain NPEOs degrade into short-chain chemicals, such as $\mathrm{NP}_{1} \mathrm{EO}$ and $\mathrm{NP}_{2} \mathrm{EO}$ in water and sediments, and those parts of them can be transformed into NP. Taking into account the transformation processes of long- to short-chain NPEOs in STPs, this proportion of short-chain NPEOs could increase further. The relationship between NP and NPEOs after sewage treatment processes should be considered; the NPEOs break down to NP and short-chain NPEOs under anoxic and aerobic conditions, and the actual NP concentration will be higher than the simulated concentration. However, the quantitative relation between increasing NP concentrations and decreasing NPEO concentrations is not simple to evaluate and simulate. With the removal of NPEOs from rivers and sediments, NP concentrations will continue to increase.

While the monitoring studies of NP in streams of the Wenyu River catchment are lacking, monitoring studies of $\mathrm{NP}$ in the sediment of this river catchment are available and have provided a database that can be used for the validation of our modeling results. A monitoring study of NP in sediments at 10 sites along the Wenyu River, from upstream of the Sha River Gate to Beiguan Gate, indicated that the NP concentration in the sediment was in the range of $124.5-8157.9 \mathrm{ng} / \mathrm{g}$ (dry weight, d.w.; Lei et al. 2008a). The predicted concentration of NP in sediment by GREAT-ER was in the range of
Fig. 5 Environmental risk profile of NP in the surface water (a) and sediment (b) in the Wenyu River catchment (river segments in red indicate an RCR greater than 1; river segments in green indicate an RCR less than 1)
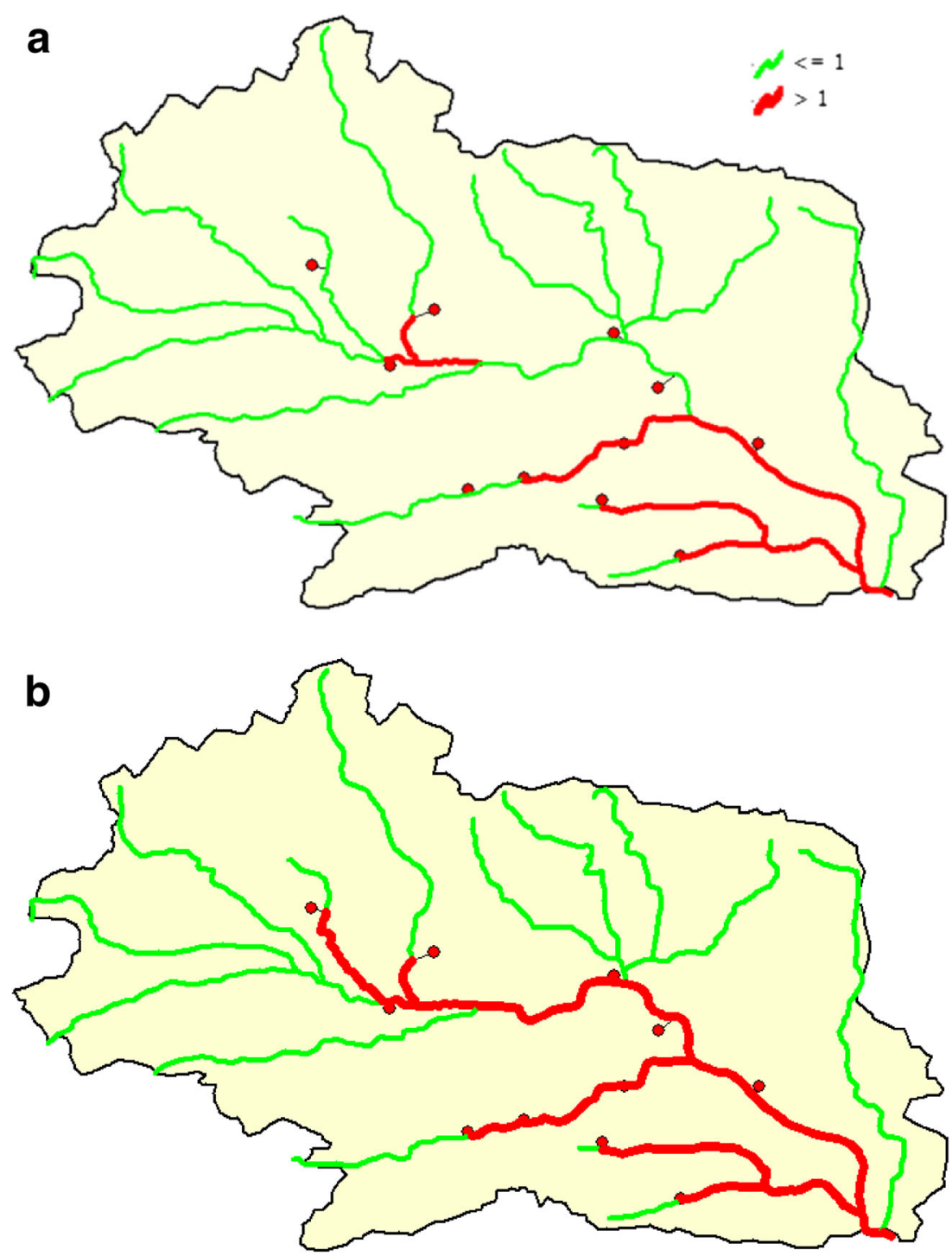
216.8-8218.3 ng/g (d.w.), which indicated a general compatibility between the modeling and monitoring results. A detailed comparison of the modeling and monitoring results of the NP concentration in the sediment among the 10 sites selected for monitoring is shown in Fig. 4. Linear regression analysis has been performed on the results of modeling and monitoring, and the correlation coefficient $\left(R^{2}\right)$ was found to be 0.94 , indicating a high level of consistency between the modeling and monitoring results. The model predicted concentrations at most sites in upstream sectors of the river that were higher than the values obtained by monitoring, which could be attributable to the difficulties that the model experienced in reflecting the dilution effect caused by the impoundment of the Sha River Reservoir. Nevertheless, the data point at $20.5 \mathrm{~km}$ is abnormal because the monitoring data were 10 times more than that by the model. Further exploration showed that there is an unreasonable discharge outlet, rather than a STP, which lead to high concentration of NP. In downstream sectors of the Wenyu River, both monitoring and modeling concentrations showed a sharp increase of NP concentrations in sediments, with a maximum value of 8157.9 and $8218.3 \mathrm{ng} / \mathrm{g}$ (d.w.), respectively, indicating serious pollution of NP in downstream sectors of the river.

\section{Risk analysis}

In this study, the risk characterization ratio (RCR; i.e., the ratio of the PEC and predicted no-effect concentration, PNEC) was used to characterize the risk profile of NP in water and sediments in the Wenyu River catchment. According to a number of ecotoxicological studies undertaken in the European Union, the PNEC of NP is about $330 \mathrm{ng} / \mathrm{L}$ in water and $39 \mathrm{ng} / \mathrm{g}$ (d.w.) in sediment (EU 2002). Figure 5 shows the environmental risk profile of NP in the surface water and sediment throughout in the Wenyu River catchment. The high RCR of NP in water generally occurs in river segments containing major STPs that serve highly industrialized and populated zones. Consequently, environmental risks are mainly presented in the upstream Shahe Reservoir, downstream Beisha River and Dongsha River, and Qing River, Ba River, and downstream Wenyu River segments. These results indicate that large STPs could generate local aquatic environmental risks from "down-the-drain" chemicals such as NP.

According to risk situation of NP in sediments, without considering background concentrations, the RCR value for NP was greater than 1 in the sediment in all river segments downstream of STPs, indicating high environmental risks due to NP in the sediment in the Wenyu River catchment. The difference RCRs of each segment between in river and in sediment is due to the respective PNEC of NP, which indicated a potential risk level in this aquatic environment.

Although the simulation results of NP risk in the target catchment are reasonable and verifiable, a number of uncertainty factors may lead to inaccurate simulation results. Firstly, the limited and singular database providing information on hydrology, population, STPs in the target catchment, and the physicochemical properties and removal rate in STPs and rivers of NP and NPEOs provides the most significant source of uncertainties in this research. Secondly, the NPsimulated environmental risk did not include NPEOs breakdown after emission from an STP, in rivers and sediment, and is likely an underestimate. Some localized parameters for the GREAT-ER model are also lacking which is likely to impact the results. Overall, the development of a more accurate risk assessment in China using the GREAT-ER model may require further study.

\section{Conclusion}

The study realized the first application of GREAT-ER as a European river catchment model for the risk assessment of "down-the-drain" chemicals in a river of China, indicating the worldwide applicability and reliability of this model. The model simulation revealed the general environmental risks presented by NP and NPEOs in the Wenyu River catchment in Beijing due to the extensive use of these chemicals, which implied the specific control or treatment measures are needed to reduce emissions of those EDCs chemicals in major cities. While the approach in this study can be an effective and applicable way to simulate chemicals in aquatic environment in the poor-data region, many aspects supporting a more precise simulation need to be developed especially including statistic data on regional chemicals consumption, more precise geographic and hydrological information of the rivers and more representative monitoring data of chemicals of concern.

Acknowledgments We thank the developers of GREAT-ER model, Dr. Diederik Schowanek from Environmental Stewardship Organization, Procter \& Gamble for their valuable encouragement and support for the model application.

\section{References}

Ahel M, Giger W, Schaffner C (1994) Behaviour of alkylphenol polyethoxylate surfactants in the aquatic environment-II. Occurrence and transformation in rivers. Water Res 28(5):11431152

Aldekoa J, Medici C, Osorio V, Perez S, Marce R, Barcelo D, Frances F (2013) Modelling the emerging pollutant diclofenac with the GREAT-ERmodel: Application to the Llobregat River Basin. J Hazard Mater 08(057):207-213

An W, Hu J (2006) Effects of endocrine disrupting chemicals on China's rivers and coastal waters. Front Ecol Environ 4(7):378-386

Arnold JG, Moriasi DN, Gassman PW, Abbaspour KC, White MJ, Srinivasan R et al (2012) SWAT: model use, calibration, and validation. Trans ASABE 55(4):1491-1508 
Balaam JL, Grover D, Johnson AC, Jürgens M, Readman J, Smith AJ et al (2010) The use of modelling to predict levels of estrogens in a river catchment: how does modelled data compare with chemical analysis and in vitro yeast assay results? Sci Total Environ 408(20): 4826-4832

Boeije G (1999) Chemical fate prediction for use in geo-referenced environmental exposure assessment. Ghent University, Belgium

Chen B, Duan JC, Mai B, Luo XJ, Yang QS, Sheng GY et al (2006) Distribution of alkylphenols in the Pearl River Delta and adjacent northern South China Sea. Chin Chemosphere 63(4):652-661

Cunningham VL, Perino C, D’Aco VJ, Hartmann A, Bechter R (2010) Human health risk assessment of carbamazepine in surface waters of North America and Europe. Regul Toxicol Pharmacol 56(3):343351

Diamanti-Kandarakis E, Bourguignon JP, Giudice LC, Hauser R, Prins GS, Soto AM et al (2009) Endocrine-disrupting chemicals: an endocrine society scientific statement. Endocr Rev 30(4):293-342

EU. (2008) Risk assessment report - environment addendum of April 2008 - 4,4'- isopropylidenediphenol (Bisphenol-A) - Part 1: Environment, http://publications.jrc.ec.europa.eu/repository/ handle/111111111/15063.

EU. (2002) Risk Assessment Report: 4-Nonylphenol (branched) and Nonylphenol. 2nd Priority list, Volume 10. European Chemicals Bureau, European Commission, EUR 20387 EN, http://ecb.jrc.it/ DOCUMENTS/Existing-Chemicals/RISK_ASSESSMENT/ REPORT/4-nonylphenol nonylphenolreport017.pdf.

Feijtel T, Boeije G, Matthies M, Young A, Morris G, Gandolfi C et al (1997) Development of a geography-referenced regional exposure assessment tool for European rivers-GREAT-ER contribution to GREAT-ER\# 1. Chemosphere 34(11):2351-2373

Fu MZ, Li ZY, Wang B (2008) Distribution of nonylphenol in various environmental matrices in Yangtze River Estuary and adjacent areas. Mar Environ Sci 27(6):561-565 (in Chinese)

Fox KK, Holt MS, Daniel M, Buckland H (2000) Removal of linear alkylbenzene sulfonate from a small Yorkshire stream: contribution to GREAT-ER project\# 7. Sci Total Environ 251:265-275

Hannah R, D'Aco VJ, Anderson PD, Buzby ME, Caldwell DJ, Cunningham VL et al (2009) Exposure assessment of 17 alphaethinylestradiol in surface waters of the United States and Europe. Environ Toxicol Chem 28(12):2725-2732

Hao RX, Liang P, Zhou YW (2007) Study on translation and conversion behavior of nonylphenol in municipal wastewater treatment. China Water Wastewater 23(1):105-108 (in Chinese)

Hou SG, Sun HW (2006) Study on pollution of nonylphenol polyethoxylates in four sewage treatment plants in the north of China. Res Environ Sci 19(3):61-66 (in Chinese)

Hou SG, Xu J, Wang L, Sun HW, Dai SG, Liu XY (2005) Primary study on nonylphenol and nonylphenol polyethoxylates in aquatic environment at Lanzhou reach of Yellow River. Environ Chem 24(3): 250-254 (in Chinese)

Hüffmeyer N, Klasmeier J, Matthies M (2009) Geo-referenced modeling of zinc concentrations in the Ruhr river basin (Germany) using the model GREAT-ER. Sci Total Environ 407(7):2296-2305

Kavlock RJ, Daston GP, DeRosa C, Fenner-Crisp P, Gray LE, Kaattari S et al (1996) Research needs for the risk assessment of health and environmental effects of endocrine disruptors: a report of the US EPA-sponsored workshop. Environ Health Perspect 104(Suppl 4): 715-740

Kehrein N, Berlekamp J, Klasmeier J (2015) Modeling the fate of downthe-drain chemicals in whole watersheds: new version of the GREAT-ER software. Environ Model Softw 10(018):1-8

Keller V (2006) Risk assessment of "down-the-drain" chemicals: search for a suitable model. Sci Total Environ 60(1-3):305-318
Koormann F, Rominger J, Schowanek D, Wagner JO, Schroder R, Wind $T$ et al (2006) Modeling the fate of down-the-drain chemicals in rivers: an improved software for GREAT-ER. Environ Model Softw 21(7):925-936

Leeuwen CJ, Vermeire TG (2007) Risk assessment of chemicals, an introduction, 2nd edn. Springer, The Netherlands, 159

Lei BL, Luo JP, Cha JM, Huang SB, Liu C, Wang ZJ (2008a) Distribution of nonylphenols and bisphenol-A in the sediments of Wenyuhe River. Environ Chem 27(3):314-317 (in Chinese)

Lei BL, Huang SB, Wang DH, Luo JP, Wang ZJ, Liu C (2008b) Present state of six estrogens in the sediment of Wenyuhe River. Environ Sci 29(9):2419-2424 (in Chinese)

Lian J, Liu JX, Wei YS (2009) Fate of nonylphenol polyethoxylates and their metabolites in four Beijing wastewater treatment plants. Sci Total Environ 407(14):4261-4268

Nielsen E, Ostergaard G, Thorup I, Ladefoged O, Jelnes J. E. (1999) Toxicological Evaluation and Limit Values for Nonylphenol, Nonylphenol Ethoxylates, Tricresyl Phosphates and Benzoic Acid. Danish Environmental Project No.512. Miljoproject.

Preuss T, Gehrhardt J, Schirmer K, Coors A, Rubach M, Ruß A, Jones PD, Giesy JP, Ratte HT (2006) Nonylphenol isomers differin estrogenic activity. Environ Sci Technol 40:5147-5153

Sabaliunas D, Webb SF, Hauk A, Jacob M, Eckhoff WS (2003) Environmental fate of triclosan in the River Aire Basin. UK Water Res 37(13):3145-3154

Schowanek. D., Price OR., Ricks B, Heinecke A, Koormann F. (2012) Development of GREAT-ER 3.0, an entirely Open Source Software for river and sediment exposure modelling. WWW.GREAT-ER. ORG.

Schowanek D, Webb S (2002) Exposure simulation for pharmaceuticals in European surface waters with GREAT-ER. Toxicol Lett 131(1): $39-50$

Shao B, Hu JY, Yang M (2002) A survey of nonylphnol in aquatic environment of Chongqing valley. Acta Sci Circumst 22(1):12-16 (in Chinese)

Sumpter JP, Johnson AC, Williams RJ, Kortenkamp A, Scholze M (2006) Modeling effects of mixtures of endocrine disrupting chemicals at the river catchment scale. Environ Sci Technol 40(17):5478-5489

Sundaram KMS, Szeto S (1981) The dissipation of nonylphenol in stream and pond water under simulated field conditions. J Environ Sci Health B 16(6):767-776

Tang LH, Lin WJ, Zhang SC, Wang PJ (2010) Simulation and analysis of non-point source pollution based on SWAT model for the Wenyu river basin. J Hydroelectric Eng 29(4):6-13 (in Chinese)

Thiele B, Heinke V, Kleist E, Guenther K (2004) Contribution to the structural elucidation of 10 isomers of technical p-nonylphenol. Environ Sci Technol 38:3405-3411

Tong YJ, Nie Y (2011) The determination of the biodegradation rate of nonylphenol polyoxyethylene ether (NPEO) in rivers. Publ Commun Sci Technol 11:122-124 (in Chinese)

USEPA. (2006) Toxic substances control act-related internet sites, http:/ www.ehso.com/tscalinks.htm.

Wang JA, Shim WJ, Yim UH, Kannan N, Li DH (2010) Nonylphenol in bivalves and sediments in the northeast coast of China. J Environ Sci 22(11):1735-1740

Welshons WV, Thayer KA, Judy BM, Taylor JA, Curran EM, Vom Saal FS (2003) Large effects from small exposures. I. Mechanisms for endocrine-disrupting chemicals with estrogenic activity. Environ Health Perspect 111(8):994-1006

Wheeler TF, Heim JR, LaTorre MR, Janes AB (1997) Mass spectral characterization of p-nonylphenol isomers using high-resolution capillary GC-MS. J Chromatogr Sci 35:19-30 
Whelan MJ, Hodges JEN, Williams RJ, Keller VDJ, Price OR, Li M et al (2012) Estimating surface water concentrations of "down-the-drain" chemicals in China using a global model. Environ Pollut 165:233240

Xu J, Wang P, Guo WF, Dong JX, Wang L, Dai SG (2006) Seasonal and spatial distribution of nonylphenol in Lanzhou Reach of Yellow River in China[J]. Chemosphere 65(9): $1445-1451$

Yoshimura K (1986) Biodegradation and fish toxicity of nonionic surfactants. J Am Oil Chem Soc 63(12):1590-1596

Yu Y, Xu J, Sun HW, Dai SG (2008) Sediment-porewater partition of nonylphenol polyethoxylates: field measurements from Lanzhou Reach of Yellow River. China Arch Environ Con Toxicol 55(2): 173-179

Zhang YY, Chen JF, Xia J, Meng DJ (2009) Research on the impact of dams and floodgates on riverine runoff and water quality in Wenyu River Basin[J]. J Nat Resour 24(10):1697-1705 (in Chinese)
Zhao JL, Ying GG, Wang L, Yang JF, Yang XB, Yang LH et al (2009) Determination of phenolic endocrine disrupting chemicals and acidic pharmaceuticals in surface water of the Pearl Rivers in South China by gas chromatography-negative chemical ionization-mass spectrometry. Sci Total Environ 407(2):962-974

Zheng FD, Meng QY, Wang PJ, Jin GQ (2007) Study on status and improvement strategies of water environment in Wenyu River of Beijing. Beijing Water 4(5):5-8 (in Chinese)

The English in the revised manuscript has been checked again by at least two professional editors, both native speakers of English. For a certificate, please see: http://www.textcheck.com/certificate/Jx02ej. 